\title{
FUZZY RULE-BASED SYSTEM FOR AVENUE MANAGEMENT
}

\author{
${ }^{1}$ S. Prakash and ${ }^{2}$ C. Sundar \\ ${ }^{1}$ SRM University, Sr. Test Engineer, \\ Franklin Templeton International Services (I) Pvt. Limited, India \\ ${ }^{2}$ School of Management, SRM University, India
}

Received 2013-12-31; Revised 2014-02-04; Accepted 2014-02-15

\begin{abstract}
Mutual Funds are becoming effective way for investors to participate in financial markets. An investor must learn to analyze and measure the risk and return of the portfolio. The performance of funds is mainly affected by characteristics such as asset size, turnover and fee structure. Investors' highest priority lies in understanding the relation between fund performance and above properties. Currently the investors depend upon advisors for their financial planning and further no customized tools are available for investment decision. In this work, a fund planner tool called Techno-Portfolio Advisor is proposed which helps the investors to understand the critical relations and support mutual funds selection across the Asset Management Companies (AMCs) in India. The Techno-Portfolio Advisor is designed based on the fuzzy inference rules by considering the investor preferences like investment amount, age, future goal and return rate. Further, the optimal funds for achieving the investor goal are evaluated based on the quantitative data available from the historical NAV from SEBI/AMFI/AMCs. Thus the Techno-Portfolio Advisor creates awareness among the investor community in choosing the optimal mutual fund scheme as well as to achieve their investment goals.
\end{abstract}

Keywords: Mutual Fund, Sharp Ratio, Fuzzy Inference Rules, Fund Planner

\section{INTRODUCTION}

A mutual fund is a professionally managed investment scheme that pools money from many investors and invests it in stocks, bonds and other securities. Currently, the worldwide value of all mutual funds totals more than \$US 26 trillion. There are various mutual fund schemes like Income, Growth, Equity, Balanced, Sector, Tax Saving Schemes, Equity Linked, Infra Structure, Gilt Funds with different objectives and different investment pattern of funds, which create confusion in the minds of investors-what to choose, where to choose. The advertisements and other mode of communications being undertaken by various fund operators (Asset Management Companies) put the investors into a state of confusion regarding the selection of suitable scheme. There might be some false advertisements, schemes involving hidden costs and clear stated objectives material/information provided as Corresponding Author: S. Prakash, SRM University, Sr. Test Engineer, Franklin Templeton International Services (I) Pvt. Limited, India caveats. All these put the investors into a trouble in their decision making. The awareness level about various schemes as per age, income, risk taking ability, period of investment, expected return, taxation, generally not up to the expected level among the investors.

This research is limited to 3 open-ended funds, 3 each in the equity, tax planning and the sector funds respectively of selected AMCs (Franklin Templeton, ICICI and HDFC) to the availability of NAV data for the past two years (2011-2012). The objective of this research work is to analyze the financial performance of selected mutual fund schemes through Sharpe Ratio, Treynor Ratio, Jenson Ratio using inference rules and list the investment amounts in each scheme to achieve investor target amount.

\section{LITERATURE SURVEY}

Literature on mutual fund portfolio selection and performance evaluation of funds is enormous. 
Sapar and Narayan (2003) done an analysis on Indian Mutual Fund Performance during Bear Market using Treynor's Ratio, Sharp Measure and concluded that few of mutual fund schemes satisfies investors' expectations in the form on expected returns in both premium for systematic and total risks. Selvam and Bhuvaneswari (2011) analyzed risk and return relationship of Indian mutual fund schemes. As per his study, majority of the sample schemes' returns were not significantly different from their market returns.Very few number of sample schemes' returns were significantly different from their market returns during the study period.

Deborah (2012) in his study explores about the common measures to evaluate the performance of funds.

Abdelaziz et al. (2007) proposes a model named Chance Constrained Compromise Programming Model (CCCP) asa deterministic transformation to multiobjectivestochastic programming portfolio model.

Ballestero et al. (2007) indicates that past data a good indicator for thefuture performance and the necessity to mathematicallydetermine the investor's utility function in order to prevent the potential flaws. They propose amethodology where itfilter portfolios thatare inefficient from a historical perspective and uses adecision table constructed by considering multiplescenarios assuming strict uncertainty.

Lin and Hsiech (2004) revealed that an integratedframework that incorporates fuzzy theory into strategicportfolio selection was developed based on the concepts of Decision Support System (DSS). The frameworkprovides managers with a flexible,andinteractive DSS to select projects for portfoliomanagement.

$\mathrm{Ji}$ et al. (2005) proposed a stochastic linear goalprogramming model for multistage portfolio management. A scenariogeneration method is recommended that acts as the basis of theportfolio management model. Single-stage method with timeseries model for the asset returns has been used for multistage portfolio management scenarios.

Gladish et al. (2007) suggest an interactive threestagefuzzy model for mutual funds portfolio. The selectionconsists of principal component analysis and sensitivityanalysis, portfolio selection for each fuzzy scenario andchoosing an optimal final portfolio.

Petkov et al. (2007) presents the combination MultipleCriteria Decision Making (MCDM) and techniques fromsoft systems approaches for decision support at particularstages of complex problem solutions.

Garlappi et al. (2007) proposed an integratedframework for the MutualFund Evaluation and performance. The Methodology is basedon the combination of discrete and Continuousmulticriteria Decision Aid (MCDA) methods for MFs selection and composition.

$\mathrm{Li}$ and $\mathrm{Xu}$ (2009) proposed his ideas of mean variance model as the future returnscannot be predicted based on the historical data.

Ko and Lin (2008) proposed a resource allocation neural network model that would optimize investment weight of portfolio selection as a resourceallocation problem in a finance market and as suchinvestor's asset optimization necessitate the distributionof a set of capital (resources) among a set of entities (assets) with the trade-off between risk and return.

Fujikawa (2010) adopts an interdisciplinary approach in conducting the study on curiosity with a toolset of experimental economics. Approach: I hypothesized that the Decision Makers (DMs) tended to exhibit curiosity behavior when two conditions were met: (1) The DMs faced small feedback-based decision problems; (2) The DMs bore tangible costs of their curiosity behavior.

Adamo et al. (2010) uses a multi-disciplinary approach and it is led by a Multiple Correspondence Analysis (MCA) which puts in evidence the principal characteristics of the mutual funds by their projection on a factorial plane. Later the multivariate analysis carries out typologies of mutual funds clusters with particular characteristics by a Cluster Analysis. The study confirmed the existence of different characteristics with reference to the ethical and non ethical mutual funds. Particularly, it puts in evidence three groups of funds which are inside homogeneous but heterogeneous between them by the characteristics considered.

Based on the literature study it is found that so far some researches deal with statistical tools or quantitative tools to analyze the performance of the mutual fund. All research will use one or two methods to compare the mutual funds of one or two schemes only. Some of the research focused only on particular fund and tells that funds advantage and disadvantage. No research has focused on comparing the similar type of open ended schemes in different AMCs. 
Hence this research has been taken to fill the gap to compare selected three schemes and three AMCs by using of different statistical and ratio analysis. Also there is no tool for directing investors in choosing the optimal funds for their investment goals. Hence the proposed tool Techno Portfolio Advisor guides the investors in achieving their target amounts by their preferences such as goal, return rate, inflation rate, target amount, age.

\section{OBJECTIVES OF THE STUDY}

- To design a tool Techno-Portfolio Advisor for the investors to plan their investmentsamount and to achieve their goal

- To recommend optimal funds and amount to be invested under each scheme based on the investor preferences

\section{SYSTEM ARCHITECTURE-TECHNO- PORTFOLIO ADVISOR}

Fuzzy Logic is an analytical tool used in the modeling of those phenomena that was not in scope of general sciences. In the technology world, investors have quick access to important details relevant to the decision process. Techno-Portfolio gives the ability for an investors based on the guidelines and formulas that serve as foundations to the Fuzzy Logic approach

The Techno-Portfolio Advisor fuzzy inference System is as shown in Fig. 1.

The rules to be used for investment decision-making could take into account by the following variables: Age, return rate, goal. For illustration variable "age" hold the set of ranges: "More than 60 (in years)", "40 to 60 (in years) and "less than 40 (in years)", the variable "return rate" holds the following ranges: " 4 to 6 (in percentage)", "6 to 8 (in percentage)", "8 to 10 (in percentage)", "10 to 15 (in percentage", 15 to 20 (in percentage)". The following set of states: "Child Future/Wealth/Health/Retirement" has been mapped to the variable "goal". Fuzzy Inference Rules of TechnoPortfolio Advisor inherit the above terms such as:

Rule 1: If age is between 18-40 and goal is Child Future and return rate is between 4-10 then portfolio style (Ultra Conservative) is More Equity and Less Debt
Rule 2: If age is between 18-40 and goal is Wealth and return rate is between 4-10 then portfolio style9Conservative) is More Equity and Less Debt

Rule 3: If age is between 18-40 and goal is Health and return rate is between 4-10 then portfolio style (Moderate) is More Equity and Less Debt

Rule 4: If age is between 40-60 and goal is Child Future and return rate is between 10-15 then portfolio style (Aggressive) is Equal Equity and Equal Debt

Rule 5: If age is between more than 60 and goal is Retirement and return rate is between 4-10 then portfolio style (Highly Aggressive) is Less Equity and More Debt

Rule 6: If ratio Checker (treynor) is Positive then fundstatus $=1$

Rule 7: If ratio Checker (sharp) is Positive then fundstatus $=1$

Rule 8: If ratio Checker (Beta) is Positive then fundstatus $=1$

Rule 9: If ratio Checker (Jensonalpha) is Positive then fundstatus $=1$

Functional block diagram of Techno-Portfolio Advisor is shown in Fig. 2.

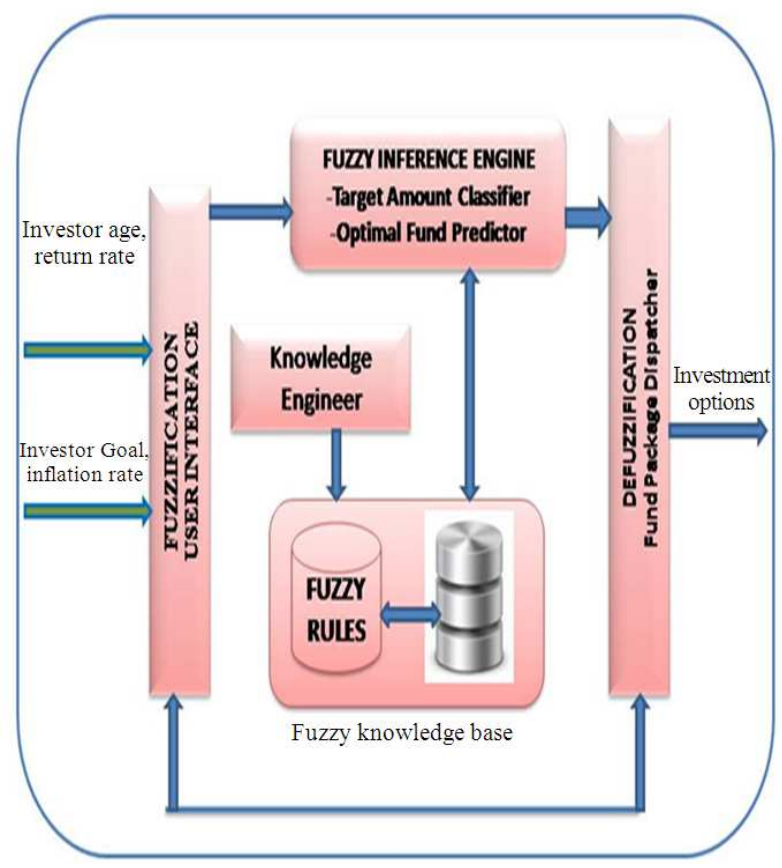

Fig. 1. Fuzzy inference system-Techno-Portfolio Advisor 


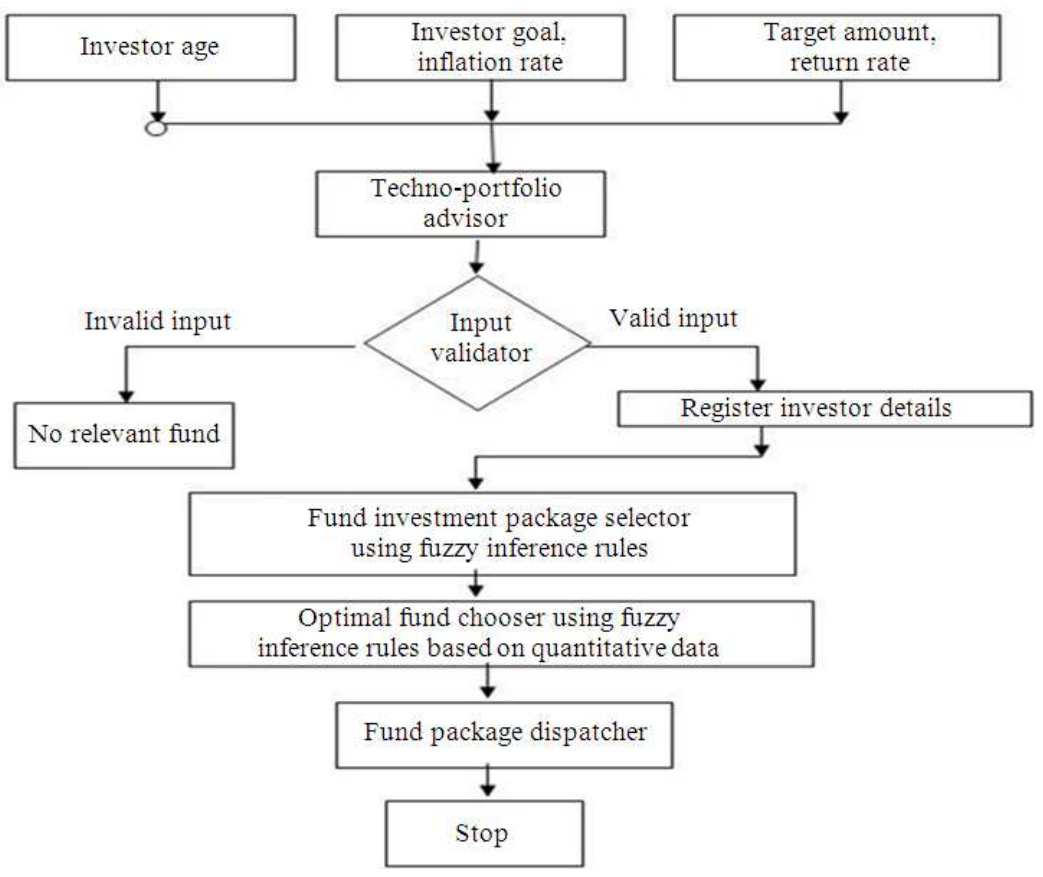

Fig. 2. Functional block diagram of Techno-Portfolio Advisor

\section{RESEARCH METHODOLOGY}

Secondary data is taken as a basis of analysis in this research. The aim is to evaluate, compare and rank the financial performance of the mutual fund schemes and to direct investors to achieve their target amount and goals through Techno-Portfolio Advisor.

In this study, three schemes and three AMCs are taken as sample. The sample AMCs are HDFC, ICICI and Franklin. Three equity mutual fund schemes each from selected AMCs is selected randomly. The data collected from the secondary source (i.e., fact sheets of the company, Newspaper, journals, periodicals).

Daily data about the closing Net Asset Value of the selected schemes has collected from the websites www.Amfiindia.com and www.Mutualfundsindia.com. The reference period for the data is taken from January 2011 to December 2012. Microsoft Excel is used for all the calculations.

\section{IMPLEMENTATION AND FUNCTIONALITY}

\subsection{Data Preparation}

Step 1: Data Cleansing

\subsection{Data Fixing Process}

This function consists of loading the data from excel files that was captured from AMFI and other related sites into a master record containing all the companies portfolio details and deleting any transaction that contain missing data or incomplete data.

Step 2: Computation

A group of activities consisting of the functions such as active stock selection, computation of Jensen Alpha, Beta, treynor and Sharp ratios are calculated.

\subsection{Integrated Development Environment (IDE) Interface}

The IDE of Techno-Portfolio Advisor allows the investor to enter the preferences that are necessary to investment options and where by what-if analysis or sensitivity analysis becomes possible. The IDE interface is shown in Fig. 3.

The Techno-Portfolio Advisor was implemented in Java. For data management, MYSQL was used. The portfolio selection is done using MATLAB. It has been tested on Windows Platform with Intel Core $2 \mathrm{CPU}$ and 80GB memory. The system receives the investor preferences as parameters for computing the optimal investment options using MATLAB from the trained database as shown in the following Fig. 4-9. 


\section{IDE interface-techno-portfolio advisor}
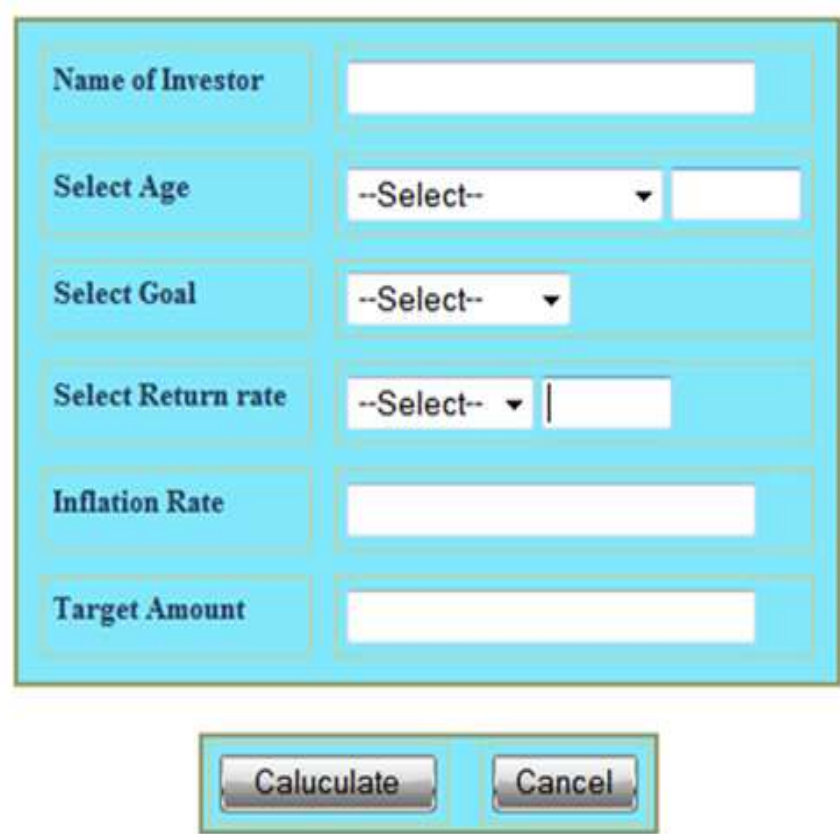

Fig. 3. IDE interface-echno-portfolio advisor

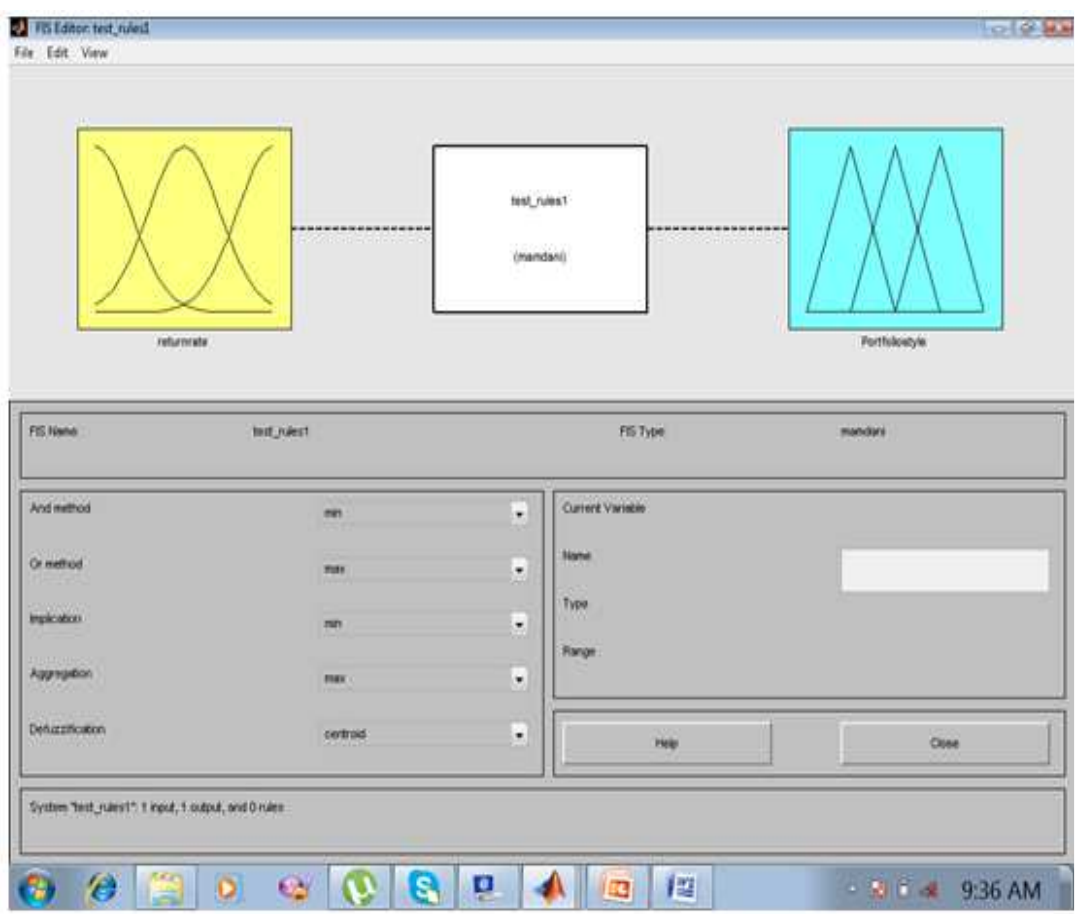

Fig. 4. Fuzzy mamdani inference engine 
S. Prakash and C. Sundar / American Journal of Applied Sciences 11 (5): 748-758, 2014

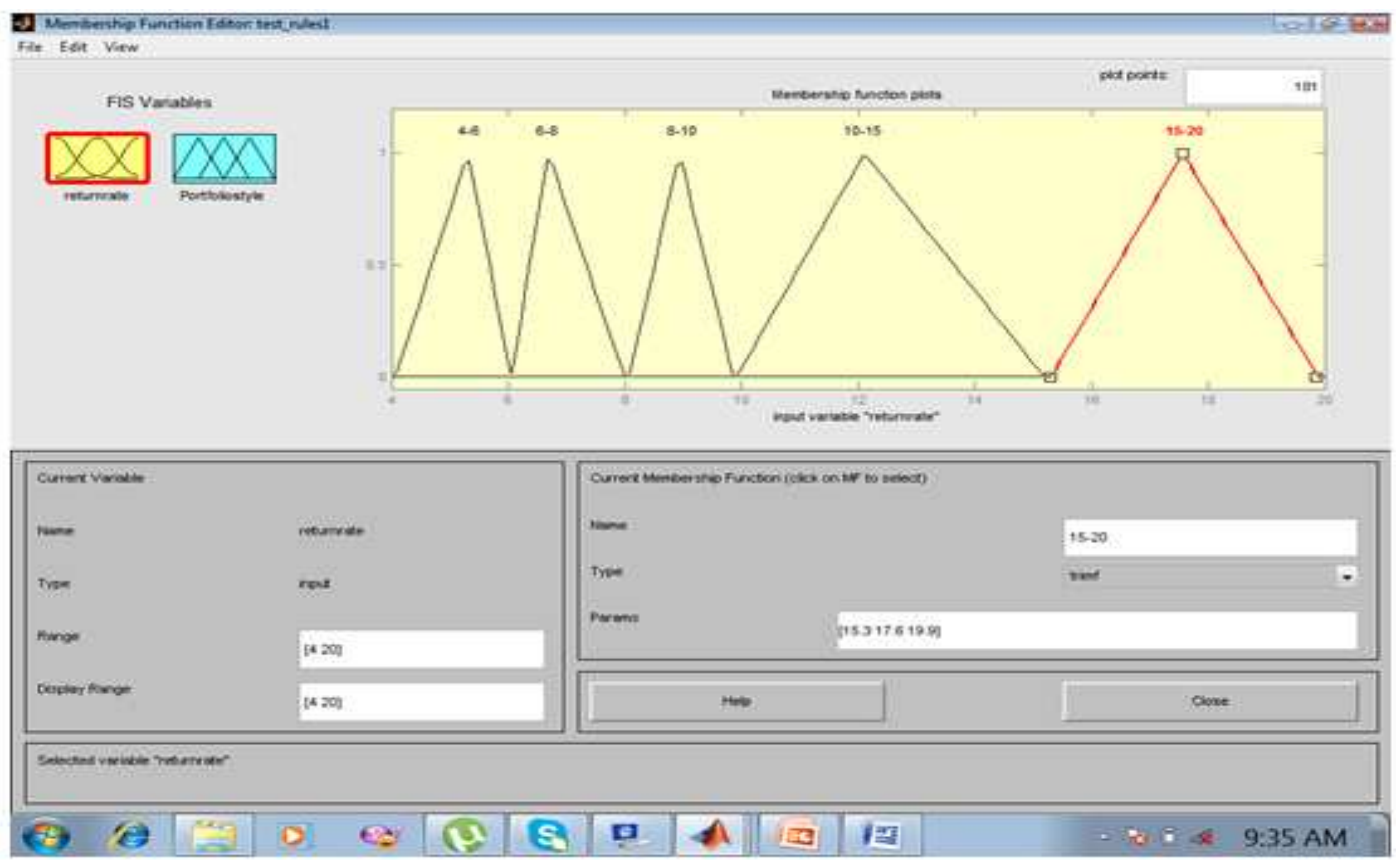

Fig. 5. Gaussian function for membership variable return rate

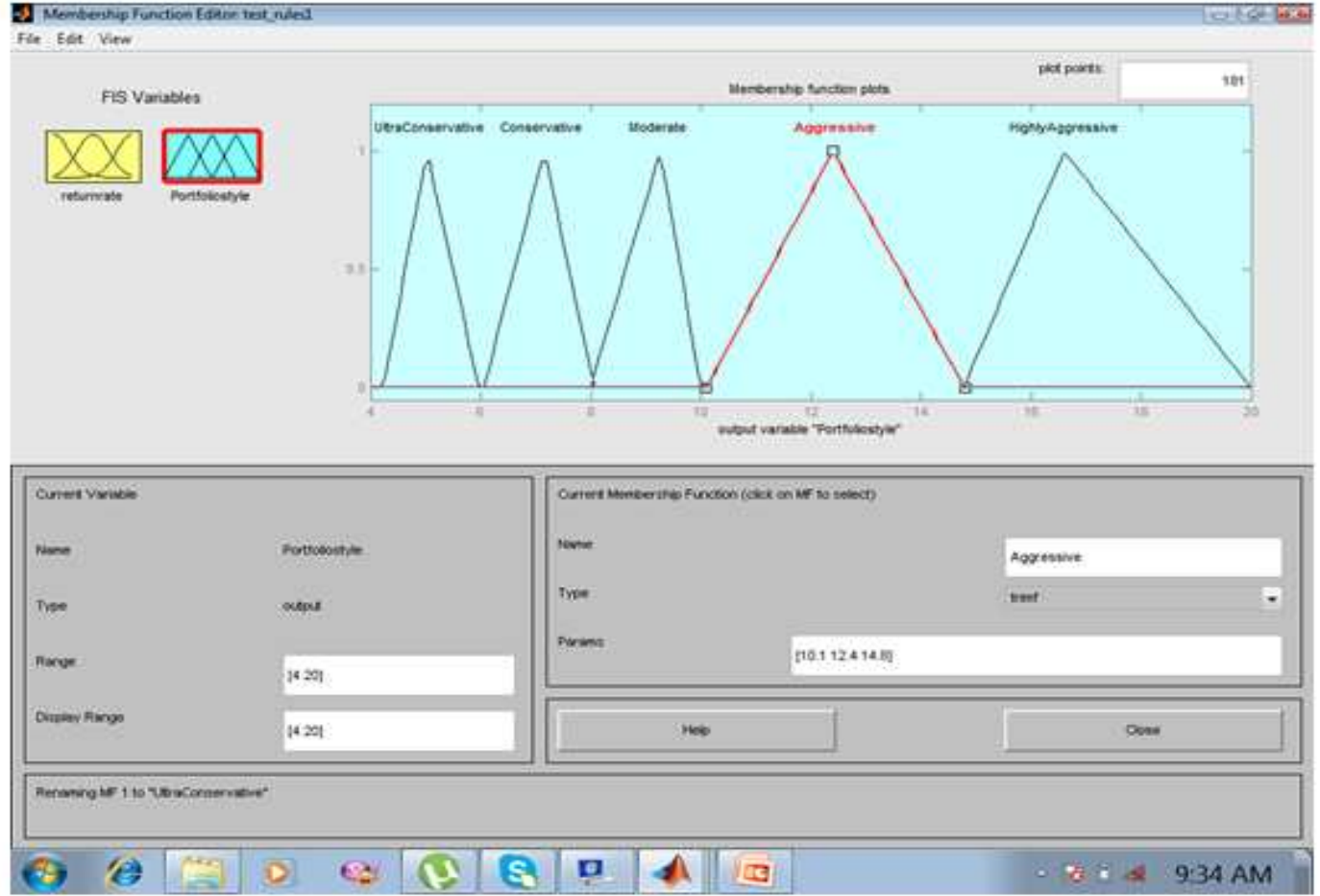

Fig. 6. Gaussian function for membership variable portfolio style 
S. Prakash and C. Sundar / American Journal of Applied Sciences 11 (5): 748-758, 2014

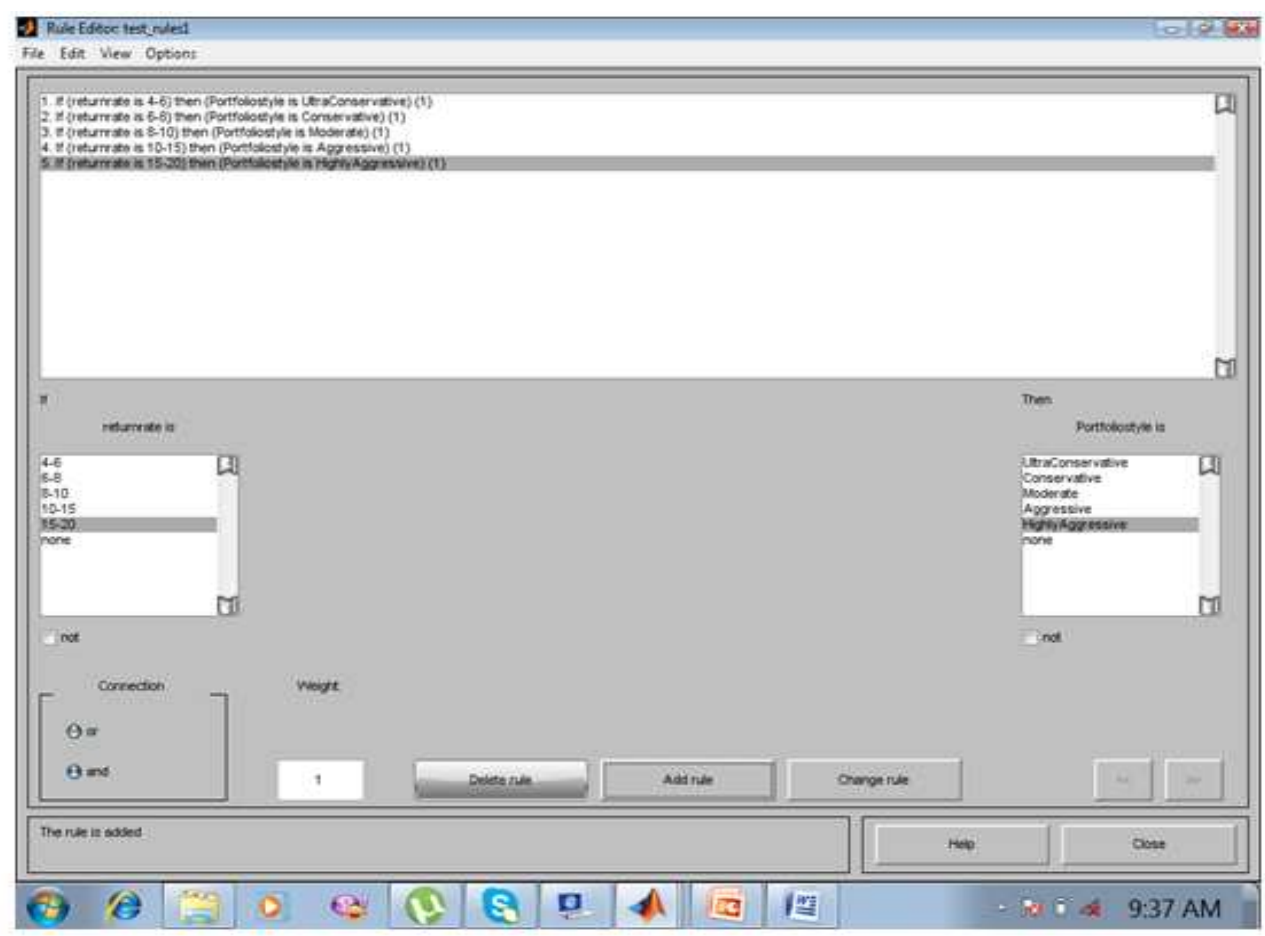

Fig. 7. Fuzzy inference rule editor

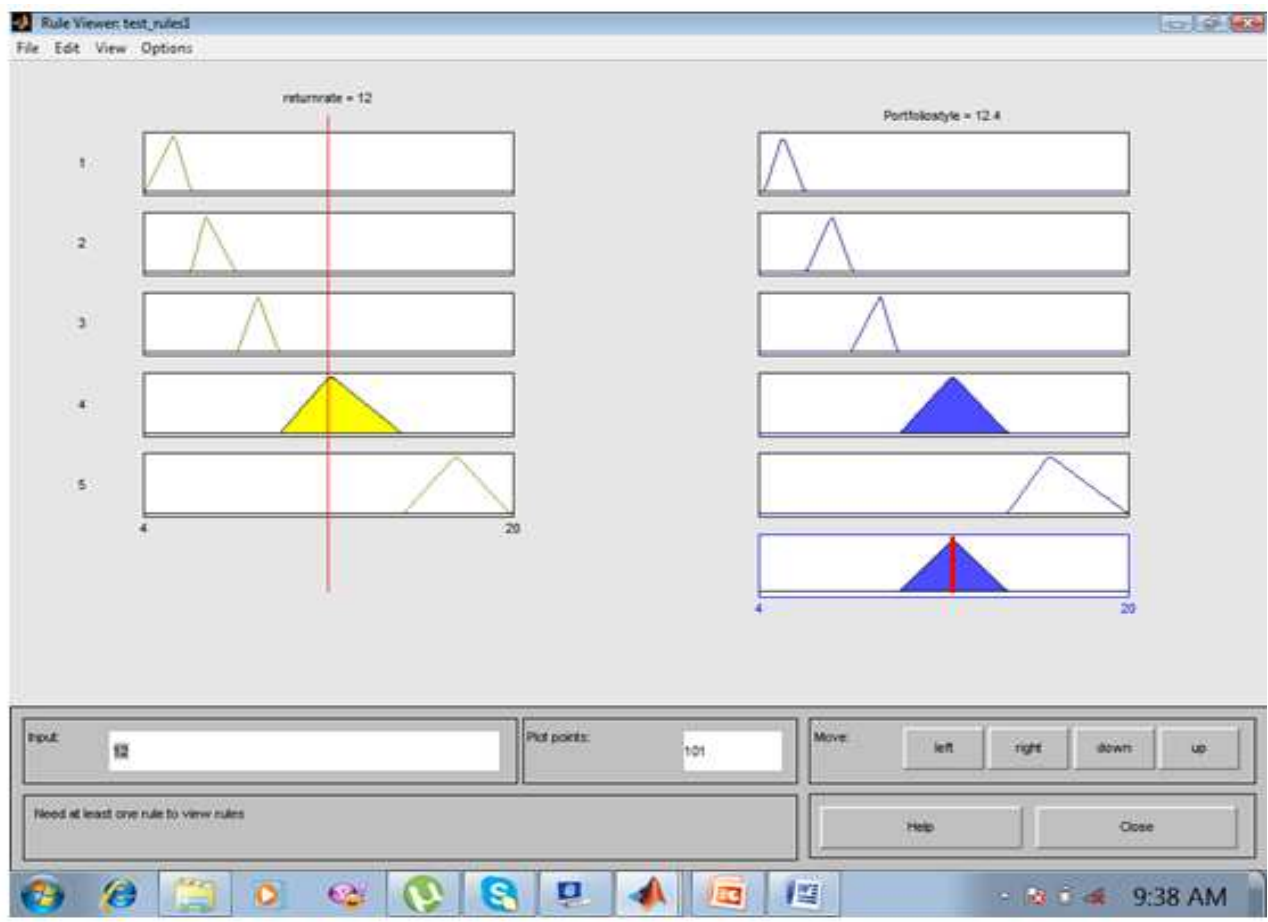

Fig. 8. Inference rule viewer 
The System outputs the investment options and is stored in a unique record. If investor enters invalid input then the system re-invoked with different new investor parameters values and the system process would be executed again.

\section{ANALYSIS AND RESULTS}

Five Test cases were create and executed with various investor parameters as shown in Fig. 10-12. The sample input screen is as in Fig. 10. The output for the above investor preferences is shown in Fig. 11 by the Techno-Portfolio Advisor. Basing on the age, return rate, inflation rate and investment amount, the portfolio style is chosen by the inference engine as aggressive. The quantitative data for computation of best funds are taken from Table 1-3.

Hence the asset allocation is 50\% debut and 50\% equity. Further based on the quantitative data such as Treynor, sharp, beta and Jensen ratios, the optimal funds for the investor are chosen by the system.

The investor has to pay 15481 monthly for 5 years or pay 177904 annually. The optimal funds are HDFC Capital Builder, Franklin India Prima-G and Franklin India Taxshield-G funds as in Fig. 11.

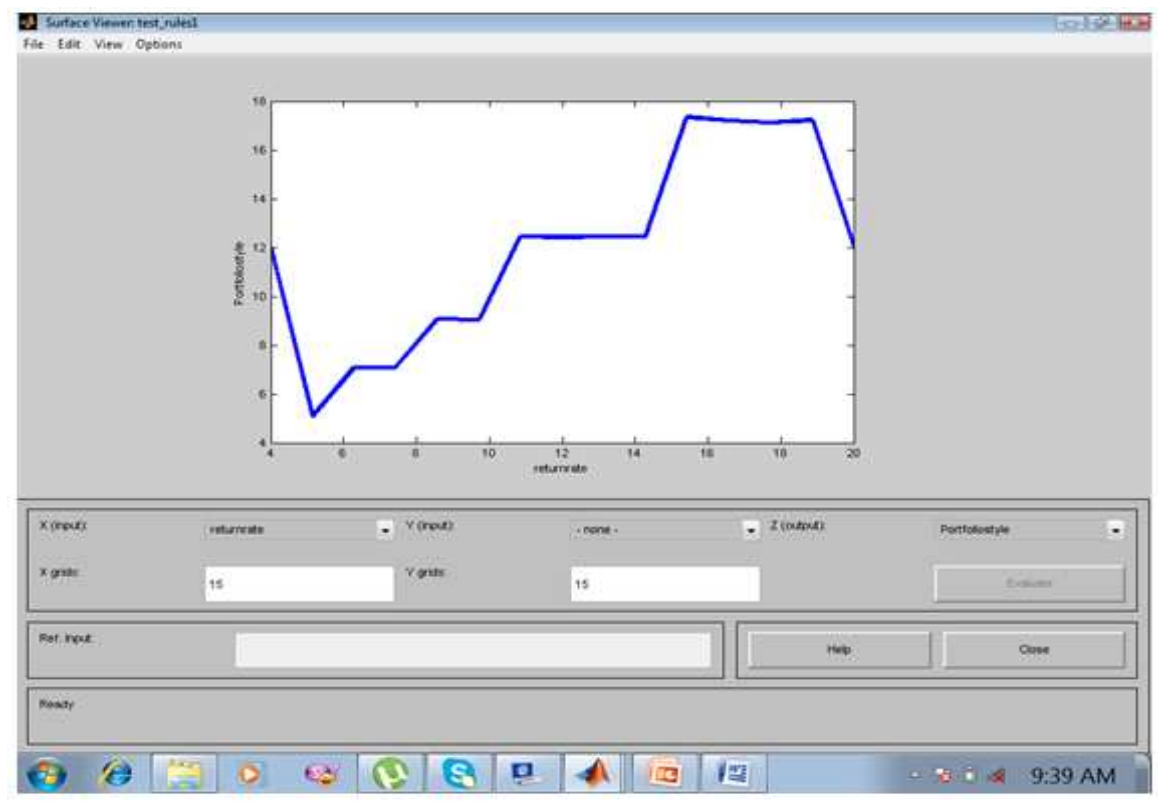

Fig. 9. Surface viewer

Table 1. Performance analysis-IT sector funds

\begin{tabular}{|c|c|c|c|c|c|c|}
\hline \multirow[b]{2}{*}{ Description } & \multicolumn{2}{|c|}{ Franklin infotech } & \multicolumn{2}{|c|}{ ICICI prudential technology reg } & \multicolumn{2}{|c|}{ HDFC capital builder } \\
\hline & 2012 & 2011 & 2012 & 2011 & 2012 & 2011 \\
\hline Beta & 0.08 & 0.10 & -0.03 & 0.69 & -0.03 & 0.39 \\
\hline Sharp ratio & -0.03 & -0.06 & 0.03 & -0.09 & 0.08 & -0.14 \\
\hline Treynor ratio & 0.00 & -0.06 & 0.07 & -0.08 & 0.11 & -0.11 \\
\hline Jensens alpha & -0.02 & -0.09 & 0.04 & -0.16 & 0.08 & -0.16 \\
\hline
\end{tabular}

Table 2. Performance analysis-small/mid cap funds

\begin{tabular}{|c|c|c|c|c|c|c|}
\hline \multirow[b]{2}{*}{ Description } & \multicolumn{2}{|c|}{ Franklin india prima-G } & \multicolumn{2}{|c|}{ ICICI pru midcap Reg-G } & \multicolumn{2}{|c|}{ HDFC mid-cap opportunities- G } \\
\hline & 2012 & 2011 & 2012 & 2011 & 2012 & 2011 \\
\hline Beta & 0.11 & 0.15 & 0.10 & 0.58 & 0.06 & 0.58 \\
\hline Sharp Ratio & 0.15 & -0.13 & 0.12 & -0.20 & 0.13 & -0.13 \\
\hline Treynor Ratio & 0.14 & -0.10 & 0.14 & -0.16 & 0.14 & -0.08 \\
\hline Jensens Alpha & 0.13 & -0.14 & 0.13 & -0.27 & 0.12 & -0.19 \\
\hline
\end{tabular}


Table 3. Performance analysis-tax planning funds

\begin{tabular}{|c|c|c|c|c|}
\hline \multirow[b]{2}{*}{ Description } & \multicolumn{2}{|c|}{ Franklin India taxshield-G } & \multicolumn{2}{|c|}{ HDFC taxsaver-G } \\
\hline & 2012 & 2011 & 2012 & 2011 \\
\hline Beta & 0.10 & 0.15 & 0.04 & 0.61 \\
\hline Sharp ratio & 0.08 & -0.09 & 0.08 & -0.15 \\
\hline Treynor ratio & 0.10 & -0.06 & 0.09 & -0.10 \\
\hline Jensens alpha & 0.09 & -0.11 & 0.08 & -0.22 \\
\hline
\end{tabular}

\section{IDE interface-techno-portfolio advisor}

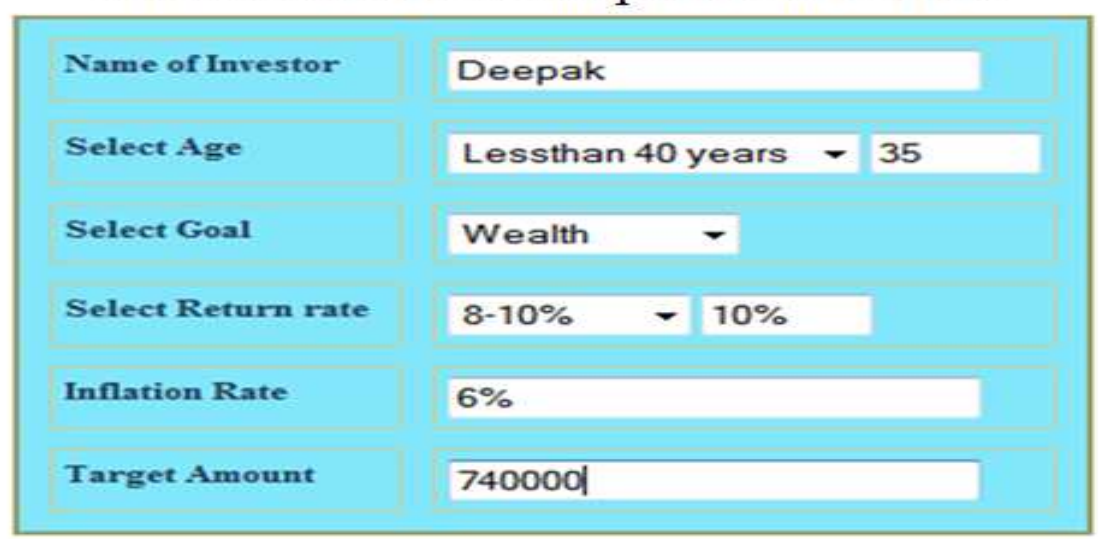

\section{Caluculate Cancel}

Fig. 10. IDE interface-Techno-Portfolio Advisor-input

\begin{tabular}{|l|l|l|r|r|c|}
\hline \multicolumn{5}{|c|}{ Techno-Portfolio Advisor } \\
\hline Name of Investor & Deepak & \multicolumn{3}{|c|}{ You Need to invest for 5 years } \\
\hline Age & 35 & Monthly & \multicolumn{3}{c|}{15481} \\
\hline Goal & Wealth & Annually & \multicolumn{3}{c|}{177904} \\
\hline Return Rate & $10 \%$ & Initial Savings Amount & \multicolumn{3}{c|}{6000} \\
\hline Inflation Rate & $6 \%$ & One Time investment Amount & \multicolumn{3}{|c|}{741840} \\
\hline & & & & & One \\
Target Amount & 740000 & Optimal Funds matching your Goal & Monthly & Annual & Time \\
\hline \multicolumn{2}{|c|}{ Asset Allocation } & HDFC Capital Builder & 3080 & 35580 & 148360 \\
\hline Equity & $50 \%$ & Franklin India Prima-G & 4620 & 53370 & 222540 \\
\hline Debt & $50 \%$ & Franklin India Taxshield-G & 7700 & 88950 & 370900 \\
\hline Portfolio Style & Aggressive & \multicolumn{1}{|c|}{ Total } & 15400 & 177900 & 741800 \\
\hline
\end{tabular}

Fig. 11. Test case 1: Techno-Portfolio Advisor-output 


\begin{tabular}{|c|c|c|c|c|c|}
\hline \multicolumn{6}{|c|}{ Techno-Portfolio Advisor } \\
\hline $\begin{array}{l}\text { Name of } \\
\text { Investor }\end{array}$ & Sachin & \multicolumn{4}{|c|}{ You Need to invest for 5 years } \\
\hline Age & 25 & Monthly & \multicolumn{3}{|c|}{3426} \\
\hline Goal & Child Education & Annually & \multicolumn{3}{|c|}{39374} \\
\hline Return Rate & $18 \%$ & Initial Savings Amount & \multicolumn{3}{|c|}{2000} \\
\hline Inflation Rate & $6 \%$ & One Time investment Amount & \multicolumn{3}{|c|}{164187} \\
\hline Target Amount & 163000 & Optimal Funds matching your Goal & Monthly & Annual & $\begin{array}{l}\text { One } \\
\text { Time }\end{array}$ \\
\hline \multicolumn{2}{|c|}{ Asset Allocation } & Franklin India Prima-G & 1700 & 19650 & 82050 \\
\hline Equity & $70 \%$ & IClCI Prudential Technology Reg & 340 & 3930 & 16410 \\
\hline Debt & $30 \%$ & HDFC Mid-Cap Opportunities- G & 1360 & 15720 & 65640 \\
\hline Portfolio Style & $\begin{array}{l}\text { Highly } \\
\text { Aggressive }\end{array}$ & Total & 3400 & 39300 & 164100 \\
\hline
\end{tabular}

Fig. 12. Test case 2: Techno-Portfolio Advisor-output

\section{CONCLUSION}

The relation between mutual fund performance and fund characteristics is of much interest to financial market practitioners and investors. However, there is a lack of conclusive knowledge on this issue. This study introduces a method which examines the relation between fund returns and fund asset size, loads, expense ratios and turnover. The study focuses developing Techno-Portfolio Advisor which provides investment options and optimal funds for achieving their objectives. The system is developed based on the fuzzy inference rule. The system fulfills the investor's objectives and preferences in terms rate of return, risk and asset allocation and diversification in order to reach an optimum solution. Therefore, Techno-Portfolio Advisor provides a solid support for decision making in mutual fund investment. The study also creates awareness among the investor community in choosing the best mutual fund scheme.

\section{REFERENCES}

Abdelaziz, B.F., B. Aouni and R. El Fayedh, 2007. Multi-objective stochastic programming for portfolio selection. Eur. J. Operat. Res., 177: 18111823. DOI: 10.1016/j.ejor.2005.10.021

Adamo, R., A. Coscarelli, D. Federico and A. Notte, 2010. The ethical and non ethical mutual funds comparison. Am. J. Econ. Bus. Admin., 2: 360-365. DOI: $10.3844 /$ ajebasp.2010.360.365
Ballestero, E., M. Gunther, D. Pla-Santamaria and C. Stummer, 2007. Portfolio selection under strict uncertainty: A multi-criteria methodology and its application to the frankfurt and vienna stock exchanges. Eur. J. Operat. Res., 181: 1476-1487. DOI: $10.1016 /$ j.ejor.2005.11.050

Deborah, K., 2012. Risk-adjusted performance measures: A case study. CFA Institute.

Fujikawa, T., 2010. A laboratory study of curiosity behavior in feedback-baased decisions. Am. J. Applied Sci., 7: 1539-1549. DOI: 10.3844/ajassp.2010.1539.1549

Garlappi, L., T. Wang and R. Uppal, 2007. Portfolio selection with parameter and model uncertainty: A multi-prior approach. Rev. Financial Stud., 20: 41-81. DOI: $10.1093 / \mathrm{rfs} / \mathrm{hhl} 003$

Gladish, B.P., D.F. Jones, M. Tamiz and A.B. Terol, 2007. An Interactive three-stage model for mutual funds portfolio selection. Omega, 35: 75-88. DOI: 10.1016/j.omega.2005.04.003

Ji, X., S. Zhu, S. Wang and S. Zhang, 2005. A stochastic linear goal programming approach to multistage portfolio management based on scenario generation via linear programming. IIE Trans., 37: 957-969. DOI: $10.1080 / 07408170591008082$

Ko, P.C. and P.C. Lin, 2008. Resource allocation neural network in portfolio selection. Expert Syst. Applic., 35: 330-337. DOI: 10.1016/j.eswa.2007.07.031 
Li, J. and J. Xu, 2009. A novel portfolio selection model in a hybrid uncertain environment. Omega, 37: 439449. DOI: 10.1016/j.omega.2007.06.002

Lin, C. and P.J. Hsiehc, 2004. A fuzzy decision support system for strategic portfolio management. Decision Support Syst., 38: 383-398. DOI: 10.1016/S01679236(03)00118-0

Sapar, N.R. and M. Ravindran, 2003. Performance evaluation of indian mutual funds. Indian Institute of Technology.
Selvam, M. and P. Bhuvaneswari, 2011. Analysis of risk and return relationship of indian equity (dividend) mutual fund schemes. Bharathidasan University.

Petkov, D., O. Petkova, T. Andrew and T. Nepal, 2007. Mixing multiple criteria decision making with soft systems thinking techniques for decision support in complex situations. Decision Support Syst., 43: 1615-1629. DOI: 10.1016/j.dss.2006.03.006 